\title{
The experience of implementing the board of trustees' policy in teaching hospitals in Iran: an example of health system decentralization
}

\author{
Leila Doshmangir ${ }^{1,2}$, Arash Rashidian ${ }^{3,4}$, Hamid Ravaghi $^{5}$, Amirhossein Takian $^{6,7,8}$, Mehdi Jafari ${ }^{9,5^{*}}$
}

\begin{abstract}
Background: In 2004, the health system in Iran initiated an organizational reform aiming to increase the autonomy of teaching hospitals and make them more decentralized. The policy led to the formation of a board of trustees in each hospital and significant modifications in hospitals' financing. Since the reform aimed to improve its predecessor policy (implementation of hospital autonomy began in 1995), it expected to increase user satisfaction, as well as enhance effectiveness and efficiency of healthcare services in targeted hospitals. However, such expectations were never realized. In this research, we explored the perceptions and views of expert stakeholders as to why the board of trustees' policy did not achieve its perceived objectives.

Methods: We conducted 47 semi-structured face-to-face interviews and two focus group discussions (involving 8 and 10 participants, respectively) with experts at high, middle, and low levels of Iran's health system, using purposive and snowball sampling. We also collected a comprehensive set of relevant documents. Interviews were transcribed verbatim and analyzed thematically, following a mixed inductive-deductive approach.

Results: Three main themes emerged from the analysis. The implementation approach (including the processes, views about the policy and the links between the policy components), using research evidence about the policy (local and global), and policy context (health system structure, health insurers capacity, hospitals' organization and capacity and actors' interrelationships) affected the policy outcomes. Overall, the implementation of hospital decentralization policies in Iran did not seem to achieve their intended targets as a result of assumed failure to take full consideration of the above factors in policy implementation into account.

Conclusion: The implementation of the board of trustees' policy did not achieve its desired goals in teaching hospitals in Iran. Similar decentralization policies in the past and their outcomes were overlooked, while the context was not prepared appropriately and key stakeholders, particularly the government, did not support the decentralization of Iran's health system.

Keywords: Decentralization, Policy Implementation, Health Policy, Organizational Reform, Health System, Iran Copyright: $\odot 2015$ by Kerman University of Medical Sciences

Citation: Doshmangir L, Rashidian A, Ravaghi H, Takian A, Jafari M. The experience of implementing the board of trustees' policy in teaching hospitals in Iran: an example of health system decentralization. Int J Health Policy Manag 2015; 4: 207-216. doi: 10.15171/ijhpm.2014.115
\end{abstract}

Article History:

Received: 25 March 2014

Accepted: 29 October 2014

ePublished: 31 October 2014

*Correspondence to:

Mehdi Jafari

Email: mjafari@iums.ac.ir

\section{Key Messages}

Implications for policy makers

- Among others, consideration of contextual factors, existence of enough and robust evidence, and identification of clear role of various stakeholders are pivotal determinants of policy implementation.

- In implementing hospitals' board of trustee policy, the lack of paying enough attention to above-mentioned prerequisites resulted in not achieving the desired targets.

- Partial implementation of the policy, without completing the remaining aspects may lead to failure in achieving policy aims.

Implications for public

The policies of giving more decision-making power to public hospitals are followed to improve efficiency and responsiveness of the hospitals in satisfying the needs of the public. However, these policies may succeed in their aims only if due attention is paid to the facilitators and the barriers of policy implementation.

\section{Background}

Decentralization is a common organizational reform in health systems that aims to transfer decision-making control, authority, costing and revenue rights from the central level (e.g. Ministry of Health) to the lower level provider organizations (e.g. hospitals) $(1,2)$. The degree of decentralization given to hospitals varies. This includes budgetary hospitals, autonomous hospitals, corporatized hospitals, and privatized hospitals. Hospital autonomy is a model of hospital organization opted by governments 
or semi-government agencies around the world aiming to increase technical and allocation efficiency of hospitals and helps them operate in a financially responsible way $(3,4)$. The corporatization reforms mimic the structure and efficiency level of private corporations under public ownership (5). A corporatized hospital has the rights (powers and privileges) to make contracts, own property or issue stocks and bonds (4). Recently, the trend towards organizational reforms in public hospitals has been increasing worldwide. Brazil (6), Colombia (7), Ghana (8,9), Pakistan (10), India (11), Indonesia (11), Kenya (12), Thailand (13), Uganda (14), Zimbabwe (11), and Malaysia (8), are among many countries that have undergone decentralization in their hospitals.

A hospital can be managed via the board of directors or board of trustees or without the board. Hospital administration via the board of trustees or board of directors (15), resulting in greater autonomy of hospitals and decreasing their dependence on higher level organizations (e.g. Ministry of Health) has been increasing in recent years (3).

Traditionally, the hospital board served as a "linkage to the community" (16). The responsibility of the hospital board is to provide needed resources and increase hospital performance. Studies support hospital board composition as a main factor influencing the effectiveness of hospital governance and administration (17).

The implementation phase of a policy is an important stage in the policy process that turns policy intentions into actions (18), however, in some cases it is neglected or separated from agenda setting and policy formulation $(19,20)$. Analysis of implementation of a policy can reveal challenges and opportunities faced by policy-makers and provide lessons and evidence for better implementation in the future (21-23). Also, evidence from policy analysis can potentially lead to increasing policy impact and provide useful information on the allocation of scarce resources (24).

This paper aims to provide an in-depth understanding of the implementation of a model of hospital decentralization (hospital board of trustees' policy) in the Iranian health system.

\section{Iran's healthcare financing system}

Iran is a country with an area of about 1.7 million square kilometers and a population of over 75 million. The primary healthcare in Iran is offered via a network of publicly funded services and is most comprehensive in rural areas (25). Ambulatory physician offices are privately owned and financed by insurance organizations and user charges. The majorities of hospital beds are based in public hospitals (including teaching hospitals) and are financed through a combination of state funding, insurance organizations and user charges. A significant part of the budget of the Ministry of Health is spent on treatment (22\%).

In public hospitals, users pay over $20 \%$ of the total costs, while in private hospitals users may cover over $50 \%$ of the costs, depending on the type of service and insurance coverage. In 2014 a major financing reform has been implemented in public hospitals in Iran to reduce out-of-pocket costs. While no formal figure exists for the impact of these recent reforms, previously conducted studies suggest that about $53 \%$ of total health expenditure in Iran is covered by households at the point of need (26).

\section{History of decentralization in Iran's hospital system}

Since the early 1990s, Iran has initiated a series of structural and decentralization reforms in the hospital system, aiming to increase the quality of hospital services, reduce government spending, and enhance hospitals' control over their revenues and expenses (27).

The first decentralization reform in Iran's health system was in 1995, the so-called hospital autonomy or the modern system of hospital administration (27). Despite various stakeholders' efforts, particularly by the organization previously known as the Budget and Planning Organization (currently called the Vice-Presidency for Strategic Planning and Supervision), both the Ministry of Health and Medical Education (MoHME) and the parliament protested the implementation of this policy. In 1996, following the approval of the 30,303 Plan (a financial plan for reimbursement of hospitals' personnel costs by the government), the parliament called for termination of hospital autonomy. However, the negative consequences of the policy, i.e. both users and healthcare providers' dissatisfaction have overshadowed Iran's health system for several years.

Aiming to improve the policy and increase satisfaction, effectiveness and efficiency of services, another reform has been started in public hospitals since 2004. This initiative advocated the formation of a board of trustees structure in hospitals in order to increase their autonomy in administration, financing, and control over human resources, and ultimately increase the quality of hospital services (28). A new payment system was also enforced to change the costs of clinical services and balance hospitals' revenues and expenses. The policy was included in Articles 45 and 88 of the Fourth Development Plan (2006-9) and Article 32 of the Fifth Development Plan (2011-5), as a main stream legislative requirement. In 2005, the hospital board of trustees' policy was initiated as a part of hospital decentralization initiatives in Iran. The main difference between these hospitals and the autonomous hospitals of 1995 was that the board of trustees' hospitals did not have financial and trade regulations and were administered by a board of trustees.

The boards of trustees include the following members: the Chancellor of the medical university, the hospital head (secretary of the board), an expert in health management, two faculty members, a representative of charitable organizations, and a mayor or a member of the municipality. The boards are expected to meet at least every three months. The decisions of the board are approved by a majority vote. Previous studies suggest that the board of trustees lack important decision-making powers (e.g. establishing human resource management policies) and their potentials are not fully utilized (27).

\section{Methods}

We conducted 47 semi-structured, face-to-face interviews and two focus group discussions (involving 8 and 10 participants, respectively) with health system experts including policy- 
makers, healthcare managers, members of selected hospitals' boards of trustees, and health caregivers of the health system. Participants were selected through purposeful and snowballing sampling. We selected interviewees that had relevant information, were most able to give valuable information and were accessible. We did not determine the number of interviewees in advance. We interviewed the key informants as required by the study process in order to reach saturation in the findings, as recommended in qualitative studies. Given that the study dealt with an important and complex policy question with different stakeholder groups, the number of interviewees was greater than what we usually observe in qualitative studies (29). Table 1 shows the characteristics of the research participants. The interview guide was tested on non-study participants to verify the number and order of questions (Appendix 1). All interviews were conducted in the participants' work place. Interviews were recorded, transcribed verbatim and analyzed shortly after the interviews.

Documents were collected purposefully and comprehensively from related organizations, including: MoHME, the Parliament of the Islamic Republic of Iran (Majlis), the Vice-Presidency for Strategic Planning and Supervision, the Iranian Medical Council, various insurance organizations and the internet. A total of 112 relevant local policy documents including laws, bylaws, national plans, newspapers and instructions were collected.

Data collection lasted 21 months (from February 2012 to October 2013). We used a framework approach (inductivedeductive) $(30,31)$ assisted by MAXQDA 10 (VERBI software, Germany) for data analysis. First, all texts were coded and then issues and subthemes were extracted. After interpreting the content in the categories, main themes were created. To enhance validity, we asked some key informants to read interview transcripts and send us their views (32), as well as two researchers to conduct coding. To increase reliability, we used structured processes to conduct interviews and analyze and interpret qualitative data (32).

\section{Results}

Five themes were extracted at the first stage of the analysis, which were reduced to three final themes: "policy implementation approach", "evidence on policy implementation", and "policy implementation context". There were also nine subthemes and 30 issues, as summarized in Table 2.

\section{Theme 1: policy implementation context}

This theme refers to the contextual issues and environment in which the policy was implemented and the factors that affected it. Findings related to this theme are summarized under four subthemes: structure and capacity of the health system, structure and capacity of the insurance system, policy actors and stakeholders, and structure and organization of the target hospitals.

\section{Structure and capacity of the health system}

An important issue in implementation of the board of trustees' policy was the structure of the health system and the way decisions and policies were made. Some interviewees stated that the centralized structure of Iran's health system has had a significant negative effect on decentralization policies. They thought that when health policy-makers expected hospitals to be administrated with a centralized and highly

Table 1. Characteristics of research participants

\begin{tabular}{|c|c|c|}
\hline Organization & Position & Numbers \\
\hline MoHME & $\begin{array}{l}\text { - Three former ministers of health } \\
\text { - Senior officers in the medical tariff unit } \\
\text { - Senior policy officials in the health policy-making council } \\
\text { - Senior officials in the budget office } \\
\text { - Former and current senior national officials }\end{array}$ & 11 \\
\hline Parliament & $\begin{array}{l}\text { - Four members of parliament } \\
\text { - Former senior policy officials in the health commission of parliament }\end{array}$ & 5 \\
\hline Insurance organizations & $\begin{array}{l}\text { - Board members } \\
\text { - Senior national officials }\end{array}$ & 7 \\
\hline Hospitals & $\begin{array}{l}\text { - Heads of hospitals } \\
\text { - Head of hospitals' financial offices } \\
\text { - Managers of hospitals } \\
\text { - Members of selected hospitals' boards of trustees } \\
\text { - Healthcare providers }\end{array}$ & 7 \\
\hline Universities of Medical Sciences & $\begin{array}{l}\text { - Managers at Medical Universities } \\
\text { - Faculty members } \\
\text { - Deputy treatment }\end{array}$ & 6 \\
\hline $\begin{array}{l}\text { Vice-Presidency for Strategic Planning and } \\
\text { Supervision (formerly budgeting and planning } \\
\text { organization) }\end{array}$ & $\begin{array}{l}\text { - Former and current heads of the organization } \\
\text { - Senior policy officials }\end{array}$ & 5 \\
\hline Iranian Medical Council & - Senior policy officials & 3 \\
\hline Others & $\begin{array}{l}\text { - PhD students in health policy, health economic and health management } \\
\text { - Forums } \\
\text { - Health policy and public policy researchers }\end{array}$ & 5 \\
\hline Total & & 47 \\
\hline
\end{tabular}

MoHME: Ministry of Health and Medical Education 
Table 2. The thematic framework explaining the themes, sub-themes and issues that represented factors that influenced the implementation of hospital board of trustees' policy in Iran

\begin{tabular}{|c|c|c|}
\hline Theme & Subtheme & Issue \\
\hline \multirow[t]{2}{*}{$\begin{array}{l}\text { Evidence on policy } \\
\text { implementation }\end{array}$} & Local evidence & $\begin{array}{l}\text { - Experiences of implementing similar policies in Iran } \\
\text { - Evaluation of pilot studies relevant to the policy }\end{array}$ \\
\hline & Global evidence & $\begin{array}{l}\text { - Evaluation of studies conducted in other countries } \\
\text { - Evaluation and comparison of implementation components in Iran and other countries } \\
\text { - Feasibility assessment }\end{array}$ \\
\hline \multirow[t]{5}{*}{$\begin{array}{l}\text { Policy } \\
\text { Implementation } \\
\text { context }\end{array}$} & $\begin{array}{l}\text { Structure and capacity of } \\
\text { health system }\end{array}$ & $\begin{array}{l}\text { - Centralization in the health system } \\
\text { - Decision-making and policy-making system } \\
\text { - Implementation enforcement by the upstream laws } \\
\text { - Lack of commitment to laws } \\
\text { - Insufficient financial resources for policy implementation }\end{array}$ \\
\hline & $\begin{array}{l}\text { Structure and capacity of } \\
\text { insurance organizations }\end{array}$ & $\begin{array}{l}\text { - Experiences of insurance organizations' performance } \\
\text { - Insurance capitation } \\
\text { - Strengthening the insurance industry in the health system (strategic purchasing, organizing } \\
\text { insurance funds) }\end{array}$ \\
\hline & $\begin{array}{l}\text { Policy actors and } \\
\text { stakeholders }\end{array}$ & $\begin{array}{l}\text { - Cooperation and coordination } \\
\text { - Role of the government in financial and political support } \\
\text { - Performance of various stakeholders } \\
\text { - Role and position of stakeholders and actors } \\
\text { - Conflict of interest among stockholders }\end{array}$ \\
\hline & $\begin{array}{l}\text { Capacity and organization of } \\
\text { target hospitals }\end{array}$ & $\begin{array}{l}\text { - Dependence of hospitals on the public health system } \\
\text { - Finance of teaching hospitals } \\
\text { - Types of hospitals } \\
\text { - Movement to performance-based budgeting (Mechanized system for the collection and timely } \\
\text { recognition of revenues) }\end{array}$ \\
\hline & Implementation processes & $\begin{array}{l}\text { - Top-down approach } \\
\text { - Methods of hospitals' selection } \\
\text { - Acceleration in implementation } \\
\text { - Superficial policy (Incomplete and imbalanced implementation) } \\
\text { - Comprehensiveness of the policy and balance among its components }\end{array}$ \\
\hline $\begin{array}{l}\text { Policy } \\
\text { Implementation } \\
\text { approach }\end{array}$ & $\begin{array}{l}\text { Implementation ideas and } \\
\text { attitudes }\end{array}$ & $\begin{array}{l}\text { - Viewpoints about the relationship between components of the policy } \\
\text { - Attitudes and behaviors of policy-makers and actors towards the policy }\end{array}$ \\
\hline
\end{tabular}

controlled structure, hospitals with the so-called "board of trustees structure" would have been more prosperous if they had been administrated like before. Moreover, the structure of public services in Iran did not allow hospitals to exercise adequate authority to determine the number of staff required. Therefore, due to the disproportionate staff-to-bed ratio, a major part of the hospitals' budget was spent on the payment of wages and salaries:

"The policy wasn't implemented properly. The centralized laws dominating our health system and hospital system prevent us from making any changes in the number of staff or other issues. So this is only a superficial change in administration and the policy was not fully enforced" [A former hospital manager].

Another challenge to the implementation of the hospital board of trustees policy was the lack of sufficient budgets and resources. This affected many of Iran's health policies. Some of the interviewees mentioned that the hospital board of trustees policy should have been postponed until its financial aspect was clarified:

"If hospitals are going to be administrated by a board of trustees without increasing public resources, the 1994 story (referring to the first hospital decentralization policy) will repeat itself. They ask us to become autonomous, but expect us to cover the cost per unit of service via the partial budget (patients). The tariffs are not realistic because public budget is low. I have to provide hospital services with these tariffs and these costs. Obviously this won't work... So when there isn't sufficient budget, the policy can't be enforced. That is, our level of commitment to the policy depends on the budget we receive" [A medical tariff officer].

Some interviewees were of the opinion that successful implementation of policies such as the board of trustees structure for a hospital depends on reinforcement of the foundation of Iran's health system. They argued that this cannot be achieved unless reinforcement of internal structures is accompanied by interactions with external systems.

Lack of adequate support to enforce the health laws and policies were among challenges that, some interviewees argued, led to the failure of the hospital board of trustees policy.

"Regarding the hospital board of trustees' policy, lack of supportive policies in the health system was the main reason behind failure of the policy. I think the Ministry of Health (and Medical Education) and especially insurance organizations did not support the implementation of the policy" [FGD, A health policy-maker].

\section{Structure and capacity of the insurance system}

Most interviewees thought that the structure and capacity of the insurance system could not respond to the demands of the hospital board of trustees' policy, leading to its failure. They 
mentioned that insurance organizations in Iran have not been very successful in the past. Delayed payments to hospitals or inability to cover traffic accident claims (the executive bylaw of the Article 92 of the Fourth Five-Year Development Plan), were among examples indicating that insurance organizations would not be successful in funding the policy. Some interviewees thought that one of the most important issues that could contribute to implementation of decentralization policies was health policy-makers' firm confidence in and full support of the insurance system, especially by providing it with enough financial resources:

"The health system must come to believe in the insurance system. The health system should also realize that its method of financing involves the insurance organizations. We shouldn't hurt insurance organizations and they shouldn't hurt us. Past trends show that we aren't professionally mature, both in the health system and in the insurance system" [A health policy researcher].

"Insurance organizations were not ready to accept this duty and play their role effectively; they did not know how to improve their financial turnover. They did not have an appropriate mechanism for hospital reimbursements" [FGD, A senior health official].

The majority of the interviewees thought that increasing the insurance premium per capita, the subsequent increase in insurance organizations' budget, and accurate determination of insurance premiums are the most important options for strengthening the insurance system in Iran, which may lead to successful implementation of the hospital board of trustees' policy. Insurance per capita must be determined in a way that covers the costs of insurance organizations. Many participants thought that accurate determining of insurance premiums and providing appropriate legal capacity for insurance organizations to finance their activities and repay through their own investments, are important measures that can reinforce Iran's insurance system.

\section{Policy actors and stakeholders}

The actors and stakeholders of the hospital board of trustees' policy were highlighted by the interviewees as important factors in the implementation of the policy. The VicePresidency for Strategic Planning and Supervision, the MoHME, and the insurance organizations were some key actors and stakeholders in the hospital board of trustees' policy. Many interviewees thought that the implementation of the policy suffered from insufficient interaction and cooperation among different actors and stakeholders, i.e. the government did not provide enough support for hospitals, especially financial support.

"We truly expected the government to provide financial support for this policy, which didn't happen" [A former senior health policy-maker].

Some experts considered the lack of cooperation among stakeholders as a historical challenge and one of the most fundamental problems in Iran's health system. A considerable number of interviewees were of the opinion that the main reason behind the hospital board of trustee policy's failure was the fact that it was not enforced by the insurance organizations:

"Insurance organizations and other related bodies didn't cooperate with the Ministry of Health on this matter. This is a fundamental problem in our health system and it is not only limited to this specific policy. It's a deep-rooted conflict between the Ministry of Health (and Medical Education) and insurance organizations which can't be easily resolved... Hospitals have always been confused whether they have a public or a board structure. I think that this was not anticipated in the law and the insurance organizations didn't fully comply with the determined tariffs" [A national policymaker].

The role of actors and stakeholders such as the health system's purchasers, suppliers, and supervisors in implementation of the policy was an important factor that affected its outcomes. Many participants thought that by enforcing the hospital board of trustees' policy, the MoHME decided to distance itself from its supplying role and pass it on to the real supplier of services: the hospitals. In other words, the split between the MoHME as the policy-maker, planner and organizer, and insurance organizations as the purchaser of healthcare services was not truly realized:

"Unfortunately, the Ministry of Health (and Medical Education) didn't separate itself from hospitals, and they never became autonomous. The MoHME assumed the role of a supplier itself. Therefore, the purchasers of services, which are the insurance organizations, had to purchase from a policy-making body that supervises and validates itself. This created an environment that I call structural corruption. If the Ministry of Health had really passed on the supplier role, it would have created a balance" [A senior health official].

\section{Structure and organization of the target hospitals}

Many interviewees considered the current structure of hospitals suitable for implementing the hospital board of trustees' policy. Some experts thought that the policy, especially its financial aspects, can create more financial independence in hospitals and eliminate their reliance on the government, which will ultimately increase the quality of medical services. In contrast, some interviewees argued that implementation of the policy should be adjusted to the structure and capacity of hospitals. For instance, these experts thought that implementation of the policy can pose serious challenges for providing the social functions of hospitals (e.g. mental health services) which do not create an income for hospitals. They proposed that these hospitals must be provided with subsidies.

"We are a public hospital. If my hospital is to be administrated by a board of trustees, will it have a similar efficiency and profitability to, say, a hospital with high bed occupancy rate or high bed turnover rate? Definitely not! So a logical approach must be followed to achieve hospital autonomy" [A hospital manager].

An important issue in organizing public hospitals is the reliance of these hospitals on the government. Some interviewees thought that this was a major barrier to hospital autonomy or the hospital board of trustees structure. The majority of interviewees mentioned that the heavy reliance of 
hospitals on the government would prevent them from full enforcement of the policy.

Moreover, some participants argued that enforcing the hospital board of trustees' policy in teaching hospitals required careful measures and appropriate financing methods that correspond to the performance and structure of these hospitals.

Moving toward operational budgeting and creating a system for timely receipt of revenues were important steps in implementation of the hospital board of trustee policy. Successful implementation of the policy required accurate recording and close monitoring of the revenues and expenses of the hospitals.

\section{Theme 2: evidence on policy implementation}

The majority of interviewees thought that research evidence have not been adequately considered ever since policy implementation started. In addition, many stated that the results of the feasibility study were overlooked. This theme can be broken down into two subthemes: local and global evidence.

\section{Local evidence}

According to the majority of interviewees, extensive studies and research needed to be carried out to find out how to implement the policy. Some experts argued that past experiences with similar policies implemented in the country, especially the hospital autonomy policy of 1994, and the possible challenges that might have come up were completely overlooked when planning this policy. One interviewee commented that:

"All we needed was to take a look at the hospital autonomy policy implemented in 1995. We should have examined the causes of its failure prior to starting this reform. This experience showed us that unless the major barriers in our health system are removed; the policy can't be successfully implemented" [A senior health official].

Some interviewees also noted that the experience of hospital board structure in some hospitals in Iran, including those affiliated with the Social Security Organization (SSO), demonstrated that such decisions would impose increased costs on designed hospitals:

"We're supposed to increase the efficiency of our health system... Sometimes the means becomes the end... How can a mere shift to board structure solve our problems? The Social Security Organization was administrated by a board of directors and many expenses were incurred by hospitals"

[An insurance policy-maker].

Other interviewees argued that conducting pilot studies before implementing a policy cannot, in and of itself, guarantee its successful implementation. They believed that although pilot studies were conducted in a few hospitals before implementing the policy, the results were never fully examined and analyzed:

"Our health system didn't wait to examine the results of the pilot study in the selected hospitals. At first only a few hospitals adopted the board of trustees' structure (18 hospitals). Then, the number of hospitals adopting the policy immediately increased prior to implementing other components of the policy... A pilot study was conducted without getting any feedback" [An academic].

\section{Global evidence}

Some experts mentioned that it was important to carefully investigate global evidence and the experiences of other countries that had implemented similar policies. Many interviewees considered this an important step in evaluating the feasibility of the policy to clarify the implementation's requirements. However, one expert commented that mere study of global evidence could not have been helpful:

"Evidence related to the policy as well as its challenges, successes, and failures should've been carefully examined. We also should've examined the context in which this policy had succeeded in another country and found out whether this could be achieved in Iran as well" [A senior health officer].

\section{Theme 3: policy implementation approach}

The implementation approach refers to how the "hospital board of trustees" policy was implemented in hospitals, which can be explained by two subthemes: policy implementation processes, and implementation ideas and attitudes.

\section{Policy implementation processes}

Some participants thought that hospitals' restructuring through establishment of the board of trustees in teaching hospitals was based on a hybrid implementation approach, namely mixing the elements of top-down and bottomup approaches. However, the majority of the interviewees mentioned that the most important aspect of the reform, i.e. finance, was implemented with a top-down approach, only taking into account the views of a few stakeholders such as MoHME, while disregarding the views of other major stakeholders such as insurance organizations and relevant corporate groups:

"We can't understand the necessity of implementing the financial aspect of the policy. The government did not even bother to ask insurance organizations when it decided on the premium to pay hospitals. They force insurance organizations to implement the policy without taking our views and interests into consideration" [A senior insurance policy-maker].

According to the majority of the experts, lack of a holistic and balanced approach to the different components of the policy was another factor that led to its failure. For instance, some interviewees mentioned other barriers such as poor funding and lack of hospitals' autonomy over different issues, including staffing. The high number of staff in hospitals was said to prevent hospitals from achieving high efficiency. Lack of a holistic view was consistently mentioned as a main barrier to the implementation of the policy, even if hospitals were funded based on the new model of payment and tariff:

"There should be a logical relationship between management, structure, resources, and authority of hospitals, and we have not created such a link. We just delegated the physical space and human resources of hospitals to some people and called them the board of trustees" [A national policy-maker]. 
"All the hospitals affiliated with the Ministry of Health and Medical Education is administrated based on the former decentralization law (approved in 1994). I mean, by establishing a board of trustees, we only made slight changes to the management of hospitals, while the tariffs and payments did not change accordingly" [A senior health official].

Some participants stated that the hospital board of trustees policy was implemented hastily and a broad range of hospitals were selected in a very short period of time, hence the number of hospitals included in the policy increased in an inappropriate time span:

"The policy was implemented with haste. The national hospital structure reform started with 18 hospitals, but the number of hospitals increased to 41 and shortly after to 54" [A former senior health official].

\section{Implementation ideas and attitudes}

Some of the interviewees highlighted that poor policy implementation decisions and lack of understanding of the relationship between different components of the decentralization reform led to an incomplete enforcement of the hospital board of trustees' policy:

"The decision was wrong. The policy failed because it wasn't feasible. Many laws are not enforced not because the officials aren't willing to enforce them, but because they weren't enforceable in the first place. Implementation of the policy wasn't well thought of and these types of laws are inherently wrong" [A senior insurance director].

Some emphasized that the policy-makers' attitudes and behaviors were other factors that prevented the full implementation of the decentralization reform. Some participants believed that the simplistic attitude and the hasty behavior of the policy-makers had a negative effect on its outcomes.

\section{Discussion}

In 2004 Iran's government introduced the second health reform for decentralization of hospitals. Achievement of efficiency through strengthening movement from budgetary hospitals towards semi-private units by granting teaching hospitals higher levels of autonomy and establishing a board of trustees in hospitals was an incentive for the policy implementation.

The MoHME began the implementation of some components of the policy in selected hospitals. Eight years after its initiation, the policy had not been completely implemented anywhere. In this paper we investigated the implementation of the hospital's board of trustees policy in the Iranian health system. Our findings showed that effective policy implementation is contingent on several factors related to the policy context, evidence on policy implementation, and the implementation approach which affected the policy implementation.

In many countries decentralization of financial and political power is perceived as a useful policy in improving hospital performance and outcomes of the health sector as a whole. England, Australia, Spain, Canada, the USA, and China are countries whose hospitals are governed under the supervision of a board of trustees or directors (33-35). Although, many other studies have autonomized their public hospitals but there is not enough evidence on the success or failure of the implementation process of these policies.

According to many studies, the policy of implementation of decentralization in health systems needs a wide variety of arrangements $(2,4)$.

Evidence emphasizes the policy-making stages, and the importance of the implementation process resulted in more attention being paid to this stage of the policy process $(36,37)$. Recognizing and identifying key factors affecting the policy implementation is critical to furthering successful implementation of the policy (38).

Selecting an appropriate implementation approach can facilitate an effective policy implementation. Strategic planning for the implementation of a policy is needed to facilitate the necessary behavioral and motivational changes in various stakeholders (39). Incomplete implementation of the board of trustees' policy made it unbalanced and superficial. Implementing some aspects of the policy such as determining a board of trustees in hospitals without granting them enough autonomy, as well as partial implementation of the financial aspects of the policy, were among the main factors that affected the policy implementation.

Changing evidence into practice and best use of this is a complex and multi-faceted process (40). Lack of appropriate knowledge about appropriate approaches and methods for effective policy implementation was an influential factor that contributed to the policy's failure. In addition, the results of pilot studies that were carried out in a number of hospitals were not appropriately considered for the main phase of policy implementation.

Policy context, referring to social, cultural, and economical factors, as well as aspects such as legislative or administrative turnover, national mood and political factors such as negotiations, interest groups and lobbyists, could potentially influence the policy implementation $(19,41)$. Stakeholders (individuals, groups and organizations) are at the heart of the policy triangle. They may act to push policies or obstruct them (19). The analysis of a policy enables policy-makers to identify which stakeholders may support or resist the policy and why (42). Our evidence from the implementing structural policy reform in hospitals in Iran showed lack of suitable cooperation and coordination among stakeholders in implementing the policy. The role and power of some stakeholders, particularly insurance organizations, was substantial in policy implementation. It seems that whenever the structure and capacity of insurance organizations are not well-matched with the policy implementation requirements, decisions regarding policy implementation tend to become less rational.

Also, actors' actual role in shaping and implementing the policy is pivotal for its successful implementation. Desired implementation of the policy requires stakeholders' legal authority and considerable autonomy in costing and financing. Our findings implied that the power and position of individuals, groups, organizations and specifically the 
interest of the stakeholders had a direct effect on the policy implementation. Hence, lack of understanding of the role and capacity of influential organizations and inadequate interaction among stakeholders, were important contributors to the policy's failure.

Implementing a new policy in any system, i.e. health system requires injection of new funds into the system. Our research revealed that insufficient budget was the most influential factor that posed numerous challenges to the implementation of the hospital board of trustees' policy in Iran and postponed financial components of the policy from being realized until now. Despite several years of developing and implementing the policy, the new announced tariff system for board of trustees hospitals has not yet been implemented. Determining financial resources and their effective management were the main issues for implementing the decentralization policy reform in hospitals. Also, it seems that providing adequate funds may strengthen insurance funds and increase insurance organizations capitation.

Overall, it seems that following the last decentralization model in Iran's hospitals (the modern financial system, 1994) the rational for choosing another decentralized model in hospitals (hospital board of trustee) was not based on the knowledge of context and "what works". The decentralized solution for managing and financing hospitals not only did not lead to improving outcomes but also incomplete implementation caused local authorities to act according to central authorities.

\section{Limitations}

One significant limitation of this study involves the ability to generalize results to other contexts. Because our qualitative analysis is specific to the situation under study, it is difficult to draw general or far-reaching conclusions from the findings of the study.

Although we used multiple methods to increase the rigor of study, we cannot claim that we could combine data appropriately and simply in order to arrive at an overall truth, and our interpretation of qualitative data may remain subjective.

The authors tried to deal with the risk of involving individual judgment regarding the analysis of data and interpretation of findings.

\section{Conclusion}

The new approach to hospitals' autonomy was implemented for the second time in public hospitals in Iran. However, similar to the past failed experience of hospital autonomy implemented in 1995, lack of prerequisites of the policy, as well as overlooking contextual factors, i.e. the reasons for unsuccessful decentralization policies in the country such as lack of government's support, led to the hospitals' board of trustees policy failure in Iran.

\section{Ethical issues}

The study was approved by the Ethics Committee of Iran University of Medical Sciences (IUMS) (Medical ethic No: 92/n/105/2322). We explained the aims and objectives of the study to all interviewees and their verbal consent was obtained prior to data collection. We assured research participants about anonymity.

\section{Competing interests}

The authors declare that they have no competing interests.
Authors' contributions

LD conceived the study, participated in data collection and data analysis, as well as preparation of the manuscript. AR contributed to the development of data collection, carried out data analysis, and contributed to the writing and several editing of the manuscript. HR carried out part of data collection, and contributed to the writing of the manuscript. AT participated in the design of study and contributed to the writing and editing of the manuscript. MJ participated in study design, contributed to data analysis and writing of the manuscript, and is guarantor. All authors read and approved the final version of paper.

Authors' affiliations

1'Department of Health Services Management, School of Management and Medical Informatics, Tabriz University of Medical Sciences, Tabriz, Iran. ${ }^{2}$ Iranian Center of Excellence in Health Management, Tabriz University of Medical Sciences, Tabriz, Iran. ${ }^{3}$ Department of Health Services Management and Economics, School of Public Health, Tehran University of Medical Sciences, Tehran, Iran. ${ }^{4}$ Knowledge Utilization Research Center, Tehran University of Medical Sciences, Tehran, Iran. ${ }^{5}$ School of Health Management and Information Sciences, Iran University of Medical Sciences, Tehran, Iran. ${ }^{6}$ Department of Global Health and Public Policy, School of Public Health, Tehran University of Medical Sciences, Tehran, Iran. ${ }^{7}$ National Academy of Medical Sciences, Tehran, Iran. ${ }^{8}$ College of Health and Life Sciences, Brunel University London, London, UK. ${ }^{9} \mathrm{Health}$ Management and Economics Research Center, Iran University of Medical Sciences, Tehran, Iran.

\section{References}

1. Mills A, Vaughan JP, Smith DL, Tabibzadeh I. Health system decentralization: concepts, issues and country experience. Geneva: World Health Organization; 1990.

2. Bossert T. Analyzing the decentralization of health systems in developing countries: decision space, innovation and performance. Soc Sci Med 1998; 47: 1513-27.

3. Wagstaff A, Bales S. The impacts of public hospital autonomization: evidence from a quasi-natural experiment. Washington, DC: Word Bank; 2012.

4. Braithwaite J, Travaglia JF, Corbett A. Can questions of the privatization and corporatization, and the autonomy and accountability of public hospitals, ever be resolved? Health Care Anal 2011; 19: 133-53. doi: 10.1007/s10728-010-0152-x

5. Harding A, Preker AS. Understanding organizational reforms. The corporatization of public hospitals. 2000. [cited 2014 July]. Available from: http://www.who.int/management/facility/hospital/ Corporatization.pdf

6. La Forgia GM, Couttolenc B. Hospital performance in Brazil: the search for excellence. Washington, DC: The World Bank: 2008. doi: 10.1596/978-0-8213-7358-3

7. McPake B, Yepes FJ, Lake S, Sanchez LH. Is the Colombian health system reform improving the performance of public hospitals in Bogota? Health Policy Plan 2003; 18: 182-94. doi: 10.1093/heapol/czg023

8. Preker AS, Harding A. Innovations in health service delivery: the corporatization of public hospitals. Washington, DC: World Bank; 2003.

9. Bossert TJ, Beauvais JC. Decentralization of health systems in Ghana, Zambia, Uganda and the Philippines: a comparative analysis of decision space. Health Policy Plan 2002; 17: 4-31. doi: 10.1093/heapol/17.1.14

10. Abdullah MT, Shaw J. A review of the experience of hospital autonomy in Pakistan. Int J Health Plann Manage 2007; 22: $45-$ 62. doi: 10.1002/hpm.855

11. Govindaraj R, Chawla M. Recent experiences with hospital autonomy in developing countries: what can we learn?: Harvard school of public health. Department of population and international health. 1996. [cited 2014 February]. Available from: http://www.harvardschoolofpublichealth.com/ihsg/publications/ pdf/No-32-2.pdf

12. Collins D, Njeru G, Meme J, Newbrander W. Hospital autonomy: 
the experience of Kenyatta National Hospital. Int J Health Plann Manage 1999; 14: 129-53.

13. Hawkins L, Srisasalux J, Osornprasop S. Devolution of Health Centers and Hospital Autonomy in Thailand: A Rapid Assessment. Washington, DC: World Bank; 2009.

14. Ssengooba F, Atuyambe L, McPake B, Hanson K, Okuonzi S. What could be achieved with greater public hospital autonomy? Comparison of public and PNFP hospitals in Uganda. Public Adm Deve 2002; 22: 415-28.

15. Lee SY, Alexander JA, Wang V, Margolin FS, Combes JR. An empirical taxonomy of hospital governing board roles. Health Serv Res 2008; 43: 1223-43. doi: 10.1111/j.1475-6773.2008.00835.x

16. Pfeffer J. Size and composition of corporate boards of directors: The organization and its environment. Adm Sci Q 1972; 17: 21828.

17. Molinari C, Morlock L, Alexander J, Lyles CA. Hospital board effectiveness: relationships between governing board composition and hospital financial viability. Health Serv Res 1993; 28: 358.

18. Hill MJ, Hupe PL. Implementing public policy: governance in theory and practice. London: Sage; 2002.

19. Buse K, Mays N, Walt G. Making health policy. England: McGraw-Hill; 2012.

20. Sabatier PA, Jenkins-Smith H. Policy Changes and Learning: An Advocacy Coalition Approach. Boulder, CO: Westview Press; 1993.

21. Mazmanian DA, Sabatier PA. Implementation and public policy. Glenview, IL: Scott Foresman; 1983.

22. John P. Analysing public policy. New York: Bloomsbury Publishing; 1998.

23. Buse K. Addressing the theoretical, practical and ethical challenges inherent in prospective health policy analysis. Health Policy Plan 2008; 23: 351-60. doi: 10.1093/heapol/czn026

24. Rutten A, Luschen $G$, von Lengerke $T$, Abel T, Kannas L, Rodriguez Diaz JA, et al. Determinants of health policy impact: comparative results of a European policymaker study. Soz Praventivmed 2003; 48: 379-91.

25. Takian A, Doshmangir L, Rashidian A. Implementing family physician programme in rural Iran: exploring the role of an existing primary health care network. Fam Pract 2013; 30: 5519. doi: 10.1093/fampra/cmt025

26. Oliyayi AR, Abolhalaj M, Zanganeh M, Zakeri MR, Rasidian A, Kazemian M, et al. [National Health Accounts Islamic Republic of Iran]. 1th ed. Tehran: Fate makers; 2008. [In Persian]

27. Jafari M, Rashidian A, Abolhasani F, Mohammad K, Yazdani $\mathrm{S}$, Parkerton $\mathrm{P}$, et al. Space or no space for managing public hospitals; a qualitative study of hospital autonomy in Iran. Int $J$ Health Plann Manage 2011; 26: 121-37. doi: 10.1002/hpm.1050

28. Manavi S, Babashahy S, Sari AA. [The Extra Cost of Granting
Autonomy to Public Hospitals]. Journal of Isfahan Medical School 2012; 29: 1-9. [In Persian]

29. Walker JL. The use of saturation in qualitative research. Can J Cardiovasc Nurs 2012; 22: 37-46.

30. Pope C, Mays N. Qualitative research in health care. 3rd edition. Hoboken: John Wiley \& Sons; 2008.

31. Rashidian A, Eccles MP, Russell I. Falling on stony ground? A qualitative study of implementation of clinical guidelines' prescribing recommendations in primary care. Health Policy 2008; 85: 148-61.

32. Carey JW, Morgan M, Oxtoby MJ. Intercoder agreement in analysis of responses to open-ended interview questions: Examples from tuberculosis research. Field Methods 1996; 8: 1-5. doi: 10.1177/1525822X96008003010133

33. Sajadi HS, Hadi M, Maleki M, Tourani S. Does Transfer of Hospital Governance to Board of Trustees per se Lead to Improved Hospital Performance? International Journal of Hospital Research 2012; 1: 97-102.

34. Eeckloo K, Van Herck G, Van Hulle C, Vleugels A. From Corporate Governance To Hospital Governance.: Authority, transparency and accountability of Belgian non-profit hospitals' board and management. Health Policy 2004; 68: 1-15. doi: 10.1016/j.healthpol.2003.07.009

35. Newhouse JP. Toward a theory of nonprofit institutions: An economic model of a hospital. Am Econ Rev 1970; 60: 64-74.

36. Anderson JE. Public policymaking. 8th edition. USA: Cengage Learning; 2014.

37. Birkland TA. An introduction to the policy process: Theories, concepts, and models of public policy making. Gremese Editore; 2005.

38. Fischer F, Miller GJ. Handbook of public policy analysis: theory, politics, and methods. Boca Raton: Taylor \& Francis Group; 2006.

39. Fretheim A, Munabi-Babigumira S, Oxman AD, Lavis JN, Lewin S. SUPPORT tools for evidence-informed policymaking in health 6: Using research evidence to address how an option will be implemented. Health Res Policy Syst 2009; 7 : S6. doi: 10.1186/1478-4505-7-S1-S6

40. Kitson AL, Rycroft-Malone J, Harvey G, McCormack B, Seers $\mathrm{K}$, Titchen A. Evaluating the successful implementation of evidence into practice using the PARiHS framework: theoretical and practical challenges. Implement Sci 2008; 3: 1. doi: 10.1186/1748-5908-3-1

41. Brownson RC, Chriqui JF, Stamatakis KA. Policy, Politics, and Collective Action. Am J Public Health 2009; 99: 1576-83.

42. Glassman A, Reich MR, Laserson K, Rojas F. Political analysis of health reform in the Dominican Republic. Health Policy Plan 1999; 14: 115-26. 


\section{Appendix 1}

\section{Interview guide}

Date and venue:

\section{Name and position of interviewee}

1. Please explain your general perception of the hospital board of trustees' policy (approved 2004) in Iran.

2. What were the aims and objectives of the policy? Why this policy was formulated and implemented?

3. How the policy entered to the policy agenda? By whom (individuals, groups or organizations)? How the policy was formulated and implemented? Which groups or organizations were opponents or proponents of the policy?

4. What is your opinion about implementation of the hospital board of trustees' policy in the following of hospital autonomy policy?

5. Which financing policies were adopted in accordance with the policy?

6. To what extent do you think the policy was properly implemented and the aims were achieved?

7. Please, explain the strengths and weaknesses of the policy. Which aspects of the policy need to be changed or improved?

8. To what extent do you think the policy was clear (in the content, objectives, expected results and outcomes)?

9. Regarding the policy, to what extent do you think Iranian public hospitals and health system have had the capacity for proper implementation of the policy? Which essentials should have been considered before the implementation of the policy?

10. In what extent do you think implementation of the policy was based on evidence (local or global)?

11. What were the effects of the policy (positive and negative) on hospitals, health system and community?

12. From your point of view, why teaching hospitals were selected for the implementation of the policy.

13. Considering the fact that several years have passed since the implementation of the policy, what are the main problems of policy implementation in hospitals?

14. What are the effects of the policy on financing of teaching hospitals? What were the main reasons of changing financing method of the hospitals?

15. So far, have you received any feedback from policy-makers and stakeholders such as insurance organizations, medical council organization, medical tariff office and people regarding the implementation of the policy? Please discuss. How did you deal with these feedbacks?

16. Do you have any evidence to show how far the policy has been accepted by the stakeholders?

17. Would you please, give your opinion about, whether the policy was successful or not? If your answer is no, explain why it has not been ended?

18. As a final question, is there any further issue you would like to add?

Note: The questions were adjusted based on each interviewee's position in health system.

With special thanks for your invaluable contribution.

\section{Focus Group Discussion Guide}

1. To what extent do you think the hospital board of trustees' policy was properly implemented in hospitals and the aims were achieved? Do you have any evidence? Please explain more.

2. To what extent do you think the policy was based on knowledge of "what works"? Please explain.

3. In your opinion, to what extent do you think the financing mechanism of the policy has been interpreted comprehensively and objectives, functions and consequences were clear?

4. To what extent do you think our health system have had capacity for implementing the policy? Before implementation of the policy what actions and activities should be implemented in hospitals?

5. Do you think implementation of the policy was based on evidence (local and global)? Please explain.

6. Please explain regarding positive and negative effects of the policy in teaching hospitals?

7. To what extent do you think proper and complete implementation of the policy will be effective in dealing with the current challenges of the hospitals and the health system? 